\title{
Sexualidade das pessoas com deficiência e Direitos Humanos: preconceito, discriminação e barreiras a vivências do desejo
}

Sexuality of people with disability and Human Rights: prejudice, discrimination and social barriers

to the experience of desire

Sexualidad de personas com discapacidad y Derechos Humanos: prejuicio, discriminación e

barreras sociales a las experiencias del deseo

Recebido: 05/11/2021 | Revisado: 12/11/2021 | Aceito: 14/11/2021 | Publicado: 16/11/2021

Gabriel Carlos da Silva Carneiro Maranhão

ORCID: https://orcid.org/0000-0002-2847-6081

Universidade Federal de Pernambuco, Brasil

E-mail: gabrielcarlos88@gmail.com

\begin{abstract}
Resumo
O presente artigo tem o intuito de problematizar como a sexualidade das pessoas com deficiência permanece um tabu no seio social, a partir de discursos que invisibilizam e discriminam o desejo sexual desses indivíduos. Busca-se analisar como o afeto entre essas pessoas é percebido como "pervertido", pois foge do parâmetro de normalização da sexualidade, além de perceber como o preconceito em torno das relações afetivas dos indivíduos com deficiência reforça o discurso de marginalização e exclusão histórica desse grupo social, intensificando os estigmas voltados àqueles que não se enquadram no padrão de indivíduo "saudável" ou "sem problemas". Pretende-se, na contramão do discurso discriminatório, contribuir para romper com os estereótipos que rondam a sexualidade da pessoa com deficiência, a partir da construção do direito à subjetividade e à vivência do desejo sexual, assim como qualquer outro indivíduo. A metodologia utilizada consiste em uma análise do objeto a partir de revisão bibliografia sobre o tema nas áreas de gênero e sexualidade, direitos humanos, e direitos das pessoas com deficiência. Utilizamos como método de procedimento o estudo de caso para analisar comentários injuriosos da blogueira Julia Salgueiro contra um bebê com síndrome de Down no Facebook e os desdobramentos na mídia. Como resultado, constatou-se que, pelo senso comum, as pessoas com deficiência ainda são vistas como "assexuais", sem desejo ou estranhos e são alvo de interdições diretas ou indiretas ao seu direito à sexualidade pela sociedade. Sendo assim é preciso avançar no debate, dando voz a esses sujeitos e suas vivências.
\end{abstract}

Palavras-chave: Deficiência; Sexualidade; Discriminação; Direito humanos.

\begin{abstract}
This paper aims to discuss how the sexuality of people with intellectual disabilities remains a taboo in the social environment, from the speeches that make invisible and discriminate sexual desire of people with disability. It seeks to analyze how affection between these people is perceived as "perverted", as it escapes the normalization parameter of sexuality and understand how the prejudice surrounding the affective relationships of individuals with disabilities reinforces the discourse of marginalization and historical exclusion of this social group, intensifying the stigmas aimed at those who do not fit the pattern of a "healthy" or "no problems" individual. It is intended, contrary to the discriminatory discourse, to contribute to breaking the stereotypes that surround the sexuality of people with intellectual disabilities, through the construction of the right to subjectivity and the experience of sexual desire, just like any other individual. The methodology used consists of an analysis of the object based on a literature review on the subject in the areas of gender and sexuality, human rights and rights of people with disabilities. We used the case study as a method of procedure to analyze injurious comments by blogger Julia Salgueiro against a baby with Down syndrome on Facebook and the developments in the media. As a result, it was found that, according to common sense, people with disabilities are still seen as "asexual", without desire, or outsiders and therefore, are the target of direct or indirect bans on their right to sexuality by society. Therefore, it is necessary to advance in the debate, giving voice to these subjects and their experiences.
\end{abstract}

Keywords: Disability; Sexuality; Discrimination; Human rights.

\section{Resumen}

Este artículo tiene como objetivo discutir cómo la sexualidad de las personas con discapacidad sigue siendo un tabú en el entorno social, a partir de los discursos que invisibilizan y discriminan el deseo sexual entre las personas con discapacidad. Se busca analizar cómo el afecto entre estas personas hay percebido como "pervertido", ya que escapa al parámetro de normalización de la sexualidad y comprender cómo el prejuicio en torno a las relaciones afectivas de las 
personas con discapacidad refuerza el discurso de marginación y exclusión histórica de este grupo social, intensificando los estigmas dirigidos a quienes no encajan en el patrón de un "sano" o "sin problemas "individuales. Se pretende, contrariamente al discurso discriminatorio, contribuir a romper los estereotipos que envuelven la sexualidad de las personas con discapacidad, mediante la construcción del derecho a la subjetividad y la vivencia del deseo sexual, como cualquier otro individuo. La metodología utilizada consiste en un análisis de objetos a partir de una revisión bibliográfica sobre el tema en las áreas de género y sexualidad, derechos humanos y derechos de las personas con discapacidad. Utilizamos como método de procedimiento el estudio de caso para analizar los comentarios insultantes de la bloguera Julia Salgueiro contra un bebé con síndrome de Down. Como resultado, se encontró que, según el sentido común, las personas con discapacidad son vistas como "asexuales", sin deseo o extraño y por lo tanto, son objeto de prohibiciones directas o indirectas de su derecho a la sexualidad por parte de la sociedad. Por tanto, es necesario avanzar en el debate, dando voz a estos temas y sus vivencias.

Palabras clave: Discapacidad; Sexualidad; Discriminación; Derechos humanos.

\section{Introdução: Pode a pessoa com deficiência amar/desejar?}

Basta uma simples consulta ao dicionário para perceber que na própria definição do vocábulo "deficiência" o mais frequente é notar a presença recorrente de palavras como insuficiência, falta, incapacidade. São sinônimos que carregam consigo o poder dos estereótipos em torno das pessoas tidas como "deficientes". A ideia de ser "carente de algo" é responsável por impor a esses indivíduos uma aparência de “dependentes”, pessoas que não são capazes de gerir sua própria vida.

Dados do último censo demográfico, realizado pelo Instituto Brasileiro de Geografia e Estatística (IBGE) em 2010, apontaram que quase $25 \%$ da população no Brasil, cerca de 45 milhões de pessoas, declararam possuir algum tipo de deficiência. Apesar do quantitativo expressivo, a utilização do termo genérico "pessoa com deficiência" não consegue abarcar toda a diversidade desse grupo social. A deficiência, portanto, não pode ser entendida como uma categoria homogênea.

Nos estudos acadêmicos e pesquisas científicas são apontadas diferentes naturezas dessas limitações: 1) deficiência física: relacionada ao comprometimento ou limitação de membro/parte do corpo humano; 2) deficiência sensorial: relativa aos sentidos, especialmente audição ou visão; 3) deficiência mental: envolve transtornos psiquiátricos que afetam a saúde mental e 4) deficiência intelectual: referente à atividade cognitiva do indivíduo.

Mesmo tendo uma função eminentemente didática, é preciso estar atento para não usar as classificações de maneira homogenizadora, pois isso pode, em vez de contribuir para o avanço do debate, potencializar as discriminações. Corroborando a ideia da pluralidade na deficiência, Organização Mundial da Saúde publicou em 2021 documento que destaca a heterogeneidade presente nesse grupo social e a necessidade de considerar as limitações dos indivíduos atrelada ao contexto social ao qual estão inseridos (Serra, et al., 2020).

No que tange à sexualidade, o tabu se torna ainda mais complexo. A noção de incapacidade das pessoas com deficiência de desejar afetivamente remonta à Antiguidade, pois desde essa época eram/são reproduzidos e reforçados argumentos que colocam esses sujeitos à margem da sociedade.

Este trabalho tem como objetivo debater como a sexualidade das pessoas com deficiência continua, mesmo numa sociedade tida como "pós-moderna", cercada de preconceitos e estigmas, sendo encarada como "anormal" ou "pervertida". O presente artigo tem o intuito de refletir sobre como o preconceito voltado às pessoas com deficiência silencia o desejo sexual e afetivo desses sujeitos, potencializando a norma-padrão do corpo "perfeito" e saudável.

A partir de um viés qualitativo, desenvolveremos um estudo de caso para analisar a repercussão dos comentários da blogueira Julia Salgueiro na rede social digital Facebook contra um bebê com síndrome de Down, que a levaram a ser processada por injúria em 2017. Mas por que resgatar uma situação de quatro anos atrás? Tal escolha busca perceber como a pessoa com deficiência pode ser alvo de negligência também pela mídia, pois apesar da imensa repercussão inicial do caso, os veículos de comunicação não prosseguiram no acompanhamento do processo judicial até o desfecho.

Seja por atos discriminatórios explícitos, como chacotas e insultos voltados às pessoas com deficiência, ou por meio de omissões das instituições públicas e da própria sociedade em enxergar para além da suposta "incapacidade", tem-se como 
resultado uma invisibilidade dos indivíduos com deficiência e um amplo consenso social que valida a negação do exercício da sexualidade por parte deles.

\section{Metodologia}

O percurso metodológico adotado concentra-se na análise do objeto a partir de referências teóricas do campo dos estudos de gênero e sexualidade, direitos humanos e direitos das pessoas com deficiência. Trata-se de uma pesquisa social amparada em um estudo de caso sobre o preconceito e discriminação na rede social Facebook, que também tangencia temas relacionados à Sociologia, Comunicação Social e Direitos Humanos.

Esta pesquisa configura-se como essencialmente qualitativa, pois busca relacionar os autores dessas áreas para discutir o tema da sexualidade de pessoa com deficiência. Dentre os nomes escolhidos para nortear este estudo estão Michel Foucault, Jeffrey Weeks, Gay Rubin, além de Fernandes, Mosquera e Schlesener, Gay Rubi, além de Vera Candau, Boaventura de Sousa Santos, dentro outros.

No que se refere ao método do estudo de caso, escolhemos tal procedimento, pois, de acordo com Godoy (1995), esse serve para analisar profundamente fenômenos sociais que complexos na tentativa de responder as questões "como?" "por quê", “[...] quando há pouca possibilidade de controle 30 sobre os eventos estudados e quando o foco de interesse é sobre fenômenos atuais, que só poderão ser analisados dentro de algum contexto de vida real" (Godoy, 1995, p. 25).

Para fins de postura epistemológica, não se trabalhará com uma visão amparada no realismo do significado, partindo de conclusões fixas e imutáveis:

Ainda que demonstrem diferenças consideráveis em suas opiniões, pensadores como Kierkegaard, Sartre, Buber, Gabriel Marcel, Levinas, Løgstrup, Nussbaum, Bauman e Noddings opõem-se ao modo como a moralidade é definida como esquema-padrão. Todos eles defendem uma ética da proximidade, do cuidar, da contiguidade ou da ligação, afirmando que a moralidade deve ser teorizada partindo-se de uma base experimental, especificamente na experiência da relação entre o eu e o você (Schwandt, 2006, p. 208, grifo do original).

Nesse sentido, a discussão do tema da sexualidade da pessoa com deficiência exige um estudo sobre as vivências desses indivíduos. Em vez de se posicionar acima do sujeito da pesquisa, o pesquisador precisa trabalhar a aproximação com os indivíduos. Assim como denunciado pelo filósofo Michel Foucault, os indivíduos são constantemente enquadrados em "normais" ou "anormais" e as condutas dos sujeitos passam a ser tidas como aceitáveis ou não perante a moral social. Em meio a tantos discursos de exclusão, a vivência do desejo e o afeto pelas pessoas com deficiência ainda parece distante ou impossível.

Afirmar que um "doentinho" poderia exercer sua sexualidade em pé de igualdade com os ditos "normais" é provocar a ordem social pautada na normalização dos corpos e da sexualidade. Pela ditadura da heteronormatividade e do patriarcado, o homem branco, heterossexual e "saudável" ainda é quem dita as normas e restrições na seara da sexualidade. Qualquer desvio a esse modelo imposto, soa como "anormalidade" e passa a ser encarado como inaceitável, proibido.

Na contramão de uma visão das relações sexuais voltadas à reprodução e à manutenção de uma sociedade segregadora, é preciso conceber a sexualidade como parte integrante da própria subjetividade de um ser humano. Conhecer-se e reconhecerse nos seus desejos e práticas sexuais, é, portanto, um direito que não pode ser negado a ninguém, incluindo as pessoas com deficiência.

Na obra "A História da Sexualidade (Volume I) - A vontade de saber”, Foucault ressalta menciona a hipótese repressiva, que considera o sexo como um tema proibido, silenciado ao longo dos períodos históricos. Porém, tal hipótese não se sustenta porque o autor defende que a sexualidade compreende um dispositivo histórico de poder, intrínseco às relações sociais. $\mathrm{O}$ autor 
defende que, desde o século XVIII, houve uma explosão discursiva em torno dos aspectos sexuais dos indivíduos, nos seguintes termos:

Em vez da preocupação uniforme em esconder o sexo, em lugar do recato geral da linguagem, a característica de nossos três últimos séculos é a variedade, a larga dispersão dos aparelhos inventados para dele falar, para fazê-lo falar, para obter que fale de si mesmo, para escutar, registrar, transcrever e redistribuir o que dele se diz (Foucault, 2014, p. 38).

Neste cenário de produção e reprodução do discurso sobre a sexualidade, o século XIX é marcado pelo surgimento do ramo da sexologia e a construção de teorias médicas sobre as perversões sexuais, reforçando a norma sexual da monogamia heterossexual voltada à reprodução. Tudo que estivesse fora desse padrão recebia o rótulo de "anormal", patológico. Ao longo do século, multiplicaram-se as pesquisas científicas voltadas a identificar e catalogar as perversões sexuais, demostrando uma forte preocupação com a sexualidade das mulheres, das crianças e das pessoas com deficiência e dos "pervertidos sexuais".

Foucault salienta nesse contexto surge, por exemplo, a figura do homossexual como "espécie". Até então, as relações sexuais envolvendo pessoas do mesmo sexo eram enquadradas como sodomia e encaradas como concernentes à vida privada. $\mathrm{O}$ século XIX, com a avanço da medicina, foi marcado pela patologização da sexualidade.

Fica evidente, a partir do discurso médico, a tentativa de controlar todos os impulsos sexuais que não estivessem pautados em uma relação marital, heterossexual e voltada à reprodução. Mais do que um controle, os especialistas da época procuram "consertar" aqueles que possuíam uma sexualidade desviante. O caso mais emblemático foi da hermafrodita Herculine Bardin que, tendo sido criada como "menina" durante a infância, foi forçada, após processo judicial, a assumir uma identidade masculina e comportar-se como uma "verdadeiro rapaz", chegando a cometer suicídio.

$\mathrm{Na}$ análise do sociólogo e historiador Jeffrey Weeks, o caso de Bardin apenas confirma a imposição histórica de um modelo hegemônico em torno da sexualidade. A obsessão pelas perversões sexuais se justifica pelo fato de que definir a "anormalidade" faz-se indispensável para sedimentar a própria ideia de que existe um comportamental sexual amparado pelo moral social. A "normalidade", desta feita, só pode ser definida a partir do que é tido como "anormal".

[...] Esse caso deveria ser visto como símbolo de um processo mais amplo: um processo completamente interconectado, pelo qual a definição precisa das "verdadeiras" características femininas e masculinas está aliada a um novo zelo em definir, nos discursos judiciário, médico e político, o que é "normal" ou "anormal". De fato, ao definir o que é anormal (uma moça com evidências corporais de masculinidade, neste caso), tornou-se plenamente possível tentar definir o que é verdadeiramente normal (uma plena correspondência entre o corpo e a identidade de gênero socialmente aceitável) (Weeks, 2000, p. 44).

Para Foucault, a criação das perversões sexuais surge como instrumento para ampliar as relações de poder pautadas pela sexualidade. Ele salienta que "a implantação das perversões sexuais é um efeito-instrumento: é através do isolamento, da intensificação e da consolidação das sexualidades periféricas que as relações do poder com o sexo e o prazer se ramificam e multiplicam, medem o corpo e penetram nas condutas" (Foucault, 2014, p. 54).

Nessa perspectiva, os sujeitos que não se encaixam no padrão social imposto, passam a ser estigmatizados e, a partir daí, surgem os processos de exclusão. A sexualidade constitui um argumento para intensificar a hierarquização social e fortalecer as relações de poder. A rejeição do prazer sexual dos homossexuais, das mulheres, dos "loucos" corrobora a estratégia de definir um comportamento sexual aceitável, legítimo, normal.

Cabe aqui salientar que às pessoas com deficiência nos espaços sociais, tradicionalmente, foi conferido num tratamento excludente, marginalizado. Ao longo da História, o processo de segregação desses indivíduos estive extremamente atrelado ao estereótipo da imperfeição, deformação. 
$\mathrm{Na}$ Grécia Antiga, por exemplo, a presente dicotomia entre o belo e o feio e a influência das figuras míticas dos deuses como imagem e semelhança dos seres humanos refletem profundamente uma necessidade de preenchimento de requisitos de aceitação social. Tal lógica culminou em um tratamento diferenciado para com os que não correspondiam ao padrão da maioria. Aqui, pode-se enquadrar as pessoas com deficiência.

No que concerne ao período da Idade Média, quando um recém-nascido possuía alguma deficiência era tido como "deformado" e, na maioria dos casos, acabava por ser abandonado pelos seus familiares. Para a época, "o nascimento de indivíduos com deficiência era encarado como castigo de Deus; eles eram vistos como feiticeiros ou como bruxos. Eram seres diabólicos que deveriam ser castigados para poderem se purificar" (Fernandes; Mosquera \& Schlesener, 2011, p. 134).

Trazendo à discussão para o século XX, as atrocidades no contexto da Segunda Guerra Mundial, pautadas numa superioridade da raça ariana, foram responsáveis por vitimar cerca de 275 mil pessoas com deficiência, entre adultos e crianças. O escancaramento dos horrores do regime nazista e fascista no pós-guerra fez emergir a preocupação com os Direitos Humanos, a exemplo da criação da ONU, em 1945, e da Declaração Universal dos Direitos Humanos, de 1948.

É a partir da segunda metade do século passado, mais especificamente na década de 1970, que surgem os movimentos sociais de defesa das pessoas com deficiências, compostos e dirigidos por indivíduos deficientes. No ano de 2006, foi elaborada a Convenção das Nações Unidas Sobre os Direitos da Pessoa com Deficiência, ratificada pelo ordenamento brasileiro em 2009.

Façamos um adendo aqui para explicar a concepção de direitos humanos adotada neste trabalho. Assumimos aqui uma noção que, como destaca Mendonça \& Cardoso (2018), coloque a dignidade humana como "matéria prima" para a construção de um novo olhar sobre o que é ser humano. Nesse sentido, é imperioso, seja dentro ou fora dos muros da Universidade, que se adote um olhar interdisciplinar. Torna-se inviável pensar os direitos humanos pela perspectiva da disciplinariedade, do compartimento conhecimentos. Assim como destaca Candau (2008), a busca por uma visão ampla desses direitos é fundamental para se passar do mero discurso retórico para a concretização da dignidade humana.

Quando de se fala em pesquisas acadêmicas, não se pode conceber a interdisciplinaridade apenas como junção de conhecimentos ou utilização de vários referenciais teóricos. No entendimento de Unbehaum (2014), o caminho teóricometodológico da interdisciplinaridade consiste em um "exercício comunicativo de aproximação [e também de estranhamento, como bem observam Adorno e Brito (2006)], de metodologias e de saberes específicos e diversificados, com interesse comum em um mesmo objeto de estudo [...]" (p.39).

Caminhando nesse sentido e ampliando as fronteiras da interdisciplinaridade para estudar os direitos humanos, será possível contribuir para uma Educação em Direitos Humanos, que não esteja adstrita apenas a um campo do saber, mas possa ser integrada nas diferentes áreas de conhecimento. Recorremos novamente a Candau (2008) para ratificar que só através da interdisciplinaridade poderemos ampliar o olhar para uma educação intercultural, plural. Como bem destaca Santos (2009), o desafio de efetivar uma perspectiva intercultural se concentra na ideia de que a maior parte da produção de conhecimento adota pressupostos eurocêntricos e coloniais. Mesmo aquelas pesquisas desenvolvidas na América Latina ainda carregam a herança da colonialidade.

Tal rompimento da visão colonialista só será possível quando houver a valorização dos saberes e vivências locais e as vozes dos grupos vulnerabilizados, dentre os quais se incluem as pessoas com deficiência, foram realmente escutadas. Ao enfatizar o trabalho de Boaventura de Sousa Santos, Lage e Vieira (2014) salientam que "a escolha de Santos pelas experiências e saberes locais foi feita com base na constatação de que tais lutas e experiências tem certo potencial de transformação social se consideradas à luz de uma nova forma de racionalidade" (p. 125).

Cabe salientar, entretanto, que no Brasil, até 2015, a deficiência de uma pessoa teria o condão de classificá-la, segundo o Código Civil de 2002, como absolutamente ou relativamente incapaz. Assim o exercício de direitos por esses indivíduos não poderia ser possível sem a intervenção de um representante ou assistente legal. A promulgação da Lei 13,146/2016, conhecida 
Estatuto da Pessoa com Deficiência ou Lei Brasileira de Inclusão rompeu, ao menos do ponto de vista legal, o vínculo entre deficiência e incapacidade. Como bem ressaltam Passos e Teixeira-Machado (2021), a referida legislação foi elaborada seguindo os parâmetros conceituais da Convenção Internacional dos Direitos das Pessoas com Deficiência, da Organização das Nações Unidas (ONU), aprovada pela Assembleia Geral em 13 de dezembro de 2006.

Pelo novo diploma legal nacional, a deficiência, por si só, não pode ser utilizada como argumento para declarar a incapacidade civil de um indivíduo. Nas palavras de Padro e Santos (2021), “[...] a referida lei, também conhecida como Estatuto da Pessoa com Deficiência (EPD), buscou a equiparação das concepções biológicas e psicológicas aliadas ao meio em que a pessoa com deficiência está inserida, a fim de que possa participar ativamente dos processos de desenvolvimento na sociedade" (p. 5).

O texto do Estatuto traz expressamente a necessidade de se garantir os direitos fundamentais das pessoas com deficiências, considerando esses indivíduos em regra, como plenamente capazes, garante-lhes, inclusive o exercício da sexualidade. É o que se pode extrair do art. $6^{\circ}$ da lei:

Art. $6^{\circ}$ - A deficiência não afeta a plena capacidade civil da pessoa, inclusive para:

I - casar-se e constituir união estável;

II - exercer direitos sexuais e reprodutivos;

III - exercer o direito de decidir sobre o número de filhos e de ter acesso a informações adequadas sobre reprodução e planejamento familiar;

IV - conservar sua fertilidade, sendo vedada a esterilização compulsória;

$\mathrm{V}$ - exercer o direito à família e à convivência familiar e comunitária; e

VI - exercer o direito à guarda, à tutela, à curatela e à adoção, como adotante ou adotando, em igualdade de oportunidades com as demais pessoas (BRASIL, 2002, grifos acrescidos)

Ao analisar as inovações pelo diploma normativo supracitado, é imperioso notar que o legislador atribui, em regra, capacidade ampla as pessoas com deficiência. Caso não haja motivo comprovado que impossibilite o exercício dos direitos, a presunção é de capacidade plena, pois "do ponto de vista jurídico, a ideia adotada pelo legislador deve ser interpretada de maneira ampla, incluindo tanto a capacidade de direito como a capacidade de exercício (Maranhão, 2019, p. 91).

No entendimento da jurista Carolina Ferraz, a existência de impedimentos físicos, cognitivos, sensoriais ou mentais não cria, necessariamente, obstáculos a busca pela realização pessoal desses indivíduos. A autora, que participou da organização da obra coletiva "Manual dos Direitos das Pessoas com deficiência", adverte que nenhum ser humano pode ser privado da busca pela felicidade, seja essa pessoa com ou sem limitações de quaisquer naturezas.

Indo mais além, quando o Executivo e Legislativo não cumprem o seu papel, cabe ao Judiciário garantir a efetivação de direitos dos grupos vulnerabilizados, porém nesse campo ainda temos muito o que avançar, especialmente na capacitação dos profissionais da área para compreender as vivências e especificidades desses indivíduos:

Quando as demandas envolvem grupos socialmente vulnerabilizados não cabe a defesa dos direitos desses indivíduos apenas em abstrato. Sendo assim, a diluição das desigualdades só pode se concretizar se os julgadores foram capazes eles mesmos, no exercício do ofício, utilizarem o Direito como ferramenta para desconstrução dos padrões de dominação e discriminação social vigentes (Maranhão, et. al, 2020, p. 191)

A inclusão dos grupos vulnerabilizados, como as pessoas com deficiência, mulheres, população negra, comunidade LGBTQIA+, dentre outros, precisa constituir uma prioridade das instâncias judiciárias, sejam elas locais, nacionais ou internacionais, rompendo com uma intenção meramente assistencialista. 


\section{Resultados: Discriminação e preconceito contra as pessoas com deficiências nas redes sociais: repercussão e desdobramentos do caso Julia Salgueiro na mídia local}

Apesar do aparente avanço legislativo, o reconhecimento da sexualidade das pessoas com deficiência está longe de ser uma unanimidade social. Há quem considere inadequado aceitar as relações afetivo-sexuais entre indivíduos que não possuem o devido "discernimento" para tanto. Novamente, impõe-se o discurso que insiste em considerar as pessoas com defíciência como um grupo homogêneo, seres humanos que não são capazes de alcançar a independência e se relacionar afetivamente. Em outras palavras, o afeto desses indivíduos, por não corresponder ao padrão de normalidade, é tido como proibido, perigoso.

Sendo assim, o preconceito e a discriminação voltados aos indivíduos com deficiência constroem barreiras para que essas pessoas não exerçam a sua sexualidade. A maioria dos argumentos se baseia em ideias do imaginário social que colocam as pessoas com deficiência em patamar de inferioridade e renega o desejo sexual de quem possui alguma limitação física, sensorial, intelectual ou mental. Portanto, um passo fundamental para enfrentar o estigma da anormalidade voltado à pessoa com deficiência é perceber como essa discriminação se manifesta no seio social e quais os argumentos são utilizados para construção de anormalidade sexual dos corpos que possuem alguma limitação física, intelectual, sensorial ou mental.

Um caso relevante e que fornece um restrito histórico do preconceito e da discriminação foi o da blogueira de moda pernambucana Julia Salgueiro. Em 2017, no Dia Internacional da Síndrome de Down, dia 21 de março, a influenciadora digital chamou atenção da mídia por comentários preconceituosos na postagem da jornalista Juliana Preto, que publicou no Facebook uma foto de seu sobrinho com síndrome de Down, de 11 meses. Julia escreveu os seguintes comentários: "É que nem filhote de cachorro. Lindos quando são pequenos mais quando crescem só pensam em trepar”. E logo em seguida, acrescentou: “É nojento. Vai sair um monte de filho toin ton. Vejamos os comentários reproduzidos na Figura 1: ${ }^{1}$

2

Figura 1 - Reprodução do Jornal do Commercio online.

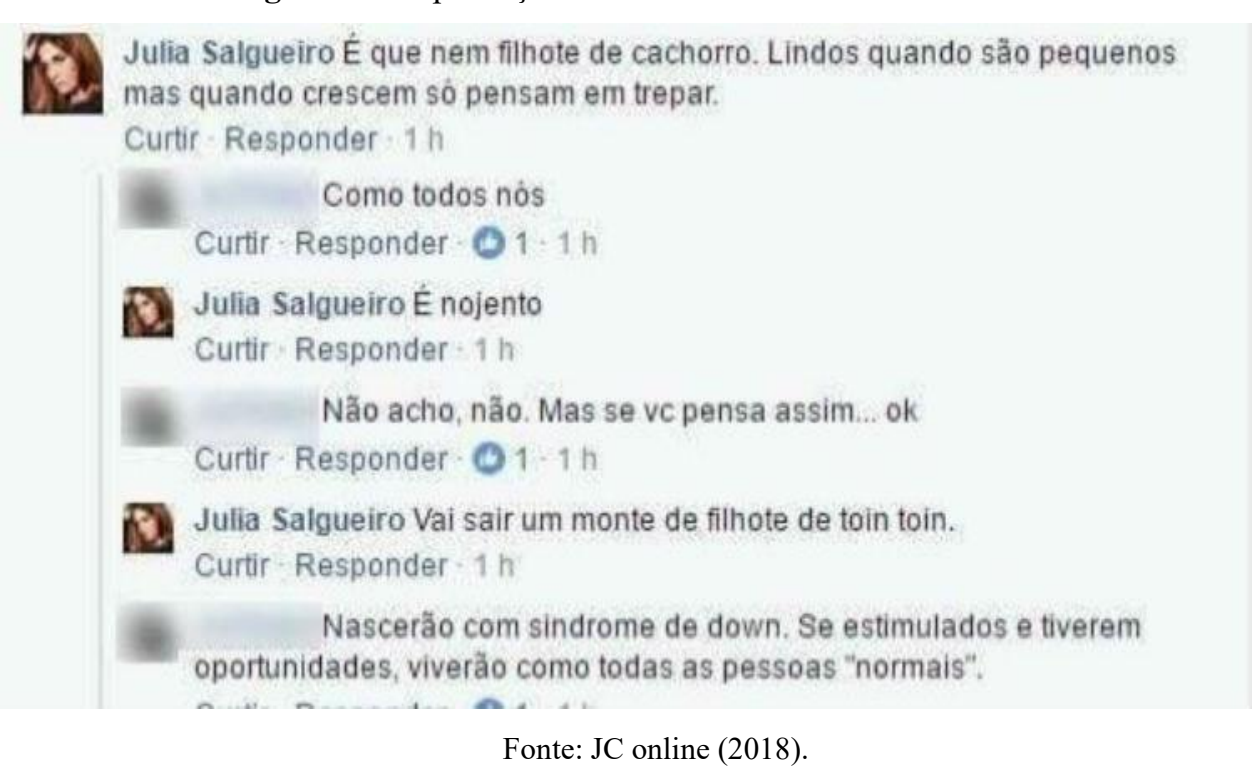

Abriremos outro parêntese aqui para justificar a escolha de um caso ocorrido em 2017. Antes de entrar no mérito dos comentários, cumpre salientar que a mídia, assim como o Estado, corriqueiramente, se exime de cumprir o papel do acompanhamento de situações que envolvem violação de direitos dos grupos vulnerabilizados.

\footnotetext{
${ }^{1} \mathrm{~A}$ imagem e reportagem completa podem ser conferidas em https://jc.ne10.uol.com.br/canal/cidades/geral/noticia /2018/04/24/blogueira-sedesculpa-por-comentarios-contra-crianca-com-down-336776.php
} 
Em consulta aos portais online dos principais veículos de massa do estado de Pernambuco, G1 Pernambuco (Rede Globo), Diario de Pernambuco, Jornal do Commercio Online (JConline) e Folha de Pernambuco, identificamos que as últimas notícias coletadas sobre o julgamento do processo sigiloso que tramitava no Tribunal de Justiça de Pernambuco (TJPE) foram publicadas pelo G1, Diario e JConline em 24 de abril de 2018. Todavia, as reportagens informavam apenas que Julia Salgueiro havia participado de uma audiência, e que, na ocasião, teria se desculpado com os pais da criança. Porém, segundo informações do portal G1, a mãe do bebê declarou que o juiz não proferiu sentença, após a ouvida da ré. Diante disso, cabe indagar: "Qual a sentença do processo?”, “Qual a pena aplicada à Julia pelo crime cometido?”. Estamos em 2021 e a pergunta continua no ar.

Após essa breve digressão, passamos às postagens da blogueira, nas quais é possível levantar a discussão de como a anormalidade do desejo sexual dos deficientes é um argumento ainda utilizado para perpetuar a ideia de uma sexualidade "saudável". O que pode parecer um comentário grosseiro e discriminatório isolado, revela, em segundo plano, a reprodução de uma hierarquia em torno da sexualidade que não permite às pessoas com deficiência o direito de construir a própria história assim como aqueles que não tem deficiência.

O primeiro comentário "só pensam em trepar" reforça a ideia de que a sexualidade desses indivíduos é vista como algo patológico. $\mathrm{O}$ argumento segue a seguinte lógica: pelo fato desses indivíduos, em alguns casos, não possuírem o discernimento completo, são incapazes de controlar os seus impulsos sexuais. O descontrole em relação ao impulso sexual aparece como justificativa para o controle da sexualidade das pessoas com deficiência.

A crença numa suposta animalidade e estranheza voltada à sexualidade desses indivíduos se revela no trecho em que Julia Salgueiro compara o bebê com Down ao filhote de cachorros. Aqui fica claro que seria intrínseco ao indivíduo com deficiência um desejo irracional que se revela na prática sexual desenfreada e, portanto, reprovável perante a sociedade.

A frase da blogueira "vai ser um monte de filho toin toin" corrobora a segregação entre os sujeitos capazes de uma "reprodução saudável" e reafirma o paradigma hegemônico que atrela o sexo unicamente à função geracional. Nas palavras de Foucault, tal preocupação tem suas origens na relação entre sexo, biologia e hereditariedade:

[...] a análise da hereditariedade colocava o sexo (as relações sexuais, as doenças venéreas, as alianças matrimoniais, as perversões) em posição de "responsabilidade biológica" com relação à espécie; não somente o sexo podia ser afetado por suas próprias doenças, mas, se não fosse controlado, podia transmitir doenças ou criá-las para as gerações futuras; ele aparece, assim, na origem de todo o capital patológico da espécie (Foucault, 2014, p.128).

Seguindo essa lógica, por não servir a uma lógica reprodutiva, a sexualidade da pessoa com deficiência torna-se objeto de controle que procura marginalizar o desejo que não se enquadra na lógica heterossexualidade compulsória, cujo objetivo primordial é a procriação. Nessa esteira, a ideia de indivíduos "doentinhos" gerando filhos também "doentinhos" surge como uma ameaça à sexualidade "normal". Nesse sentido, Rubin (2003), no artigo "Pensando o sexo: notas para uma teoria radical das políticas da sexualidade", ressalta que os diferentes discursos sobre o sexo têm o condão de delimitar uma parcela dos sujeitos tidos como consagrados, seguros e saudáveis.

Na última parte da postagem, a menção a uma suposta natureza "nojenta" do sexo entre os indivíduos com deficiência sugere uma possibilidade de estratificação das práticas sexuais. Por assim dizer, segundo os estudos Rubin, através da hierarquização sexual, estabelece-se uma linha imaginária entre o bom e o mau sexo.

Na contramão da visão dualista sobre a sexualidade, a afirmação de Rubin de que uma análise progressista da sexualidade é ainda pouco desenvolvida se mostra extremamente atual. Isso porque a concepção de que qualquer relação afetiva e sexual envolvendo duas pessoas com deficiência perverte a ordem da normalidade corrobora o argumento de que os atos sexuais são avaliados de acordo com um sistema hierárquico ditado pela sociedade patriarcal e excludente. 
Na tentativa de romper com a noção de uma sexualidade ideal, a reflexão sobre o desejo das pessoas com deficiência carece de um maior aprofundamento dentro dos estudos sobre as opressões sociais. Mesmo quando as pesquisas procuram enfatizar a deficiência, a maioria dos estudos centra-se na construção desse grupo social com forte ênfase na própria deficiência. Tal dificuldade é apontada por Olense (2006) quando analisa os estudos feministas como mulheres com deficiência:

Ao elaborarem resenhas que tratam do surgimento do tema das mulheres portadoras de deficiência como uma questão problemática para as feministas, Asch e Fine (1992) chamaram atenção para o fato de que até mesmo as pesquisas que se solidarizavam com o tema das mulheres portadoras de deficiência estavam inclinadas a enxergar essas mulheres exclusivamente em termos de suas deficiências, ignorando seus papéis de trabalhadoras, amantes, mães, amigas, esportistas e ativistas (p.225).

\section{Considerações Finais: a pessoa para além da deficiência}

A proposta de uma análise interseccional das opressões sociais se mostra inteiramente cabível para perceber o preconceito e discriminação em torno da deficiência. Entrelaçando os eixos de classe, gênero e raça, Mattos (2011) traz à tona a necessidade de se perceber novas facetas das desigualdades sociais para uma melhor compreensão das relações de poder e dominação. Só assim será possível aprofundar os estudos sobre as exclusões sociais dos grupos vulneráveis.

Entretanto, por mais urgente que seja a produção das pesquisas acadêmicas pelo viés da interseccionalidade, a própria Mattos salienta a existência de um "deficit teórico central", que resulta em pesquisas concentradas em apenas um dos níveis de investigação, no máximo dois.

A percepção da deficiência como eixo de desigualdade, portanto, se revela extremamente salutar para a desconstrução de uma sexualidade dissidente desses indivíduos. Uma melhor percepção dos pesquisadores e pesquisadoras sobre a construção do desejo sexual das pessoas com deficiente contribuiria para desconstruir o ideal machista, patriarcal, branco e heterossexual da sexualidade dominante. Tal padrão, não apenas afeta as pessoas com deficiência, mas também as mulheres, população negra, LGBTQIA+, dentre outros. Indo mais além, como salienta Maranhão, Andrade Lima e Souza (2017) a construção de estereótipos em torno de uma masculinidade hegemônica causa sérios danos aos próprios homens, que precisam sustentar o peso das normas que os fazem "Homem com H".

Não se trata de investigar a deficiência pelos seus aspectos médicos, patológico, mas estimular no campo das Ciências Sociais o interesse por desmistificar uma suposta sexualidade "anômala" desses sujeitos. Os trabalhos acadêmicos futuros, portanto, devem aprofundar a temática a partir das vozes das próprias pessoas com deficiência, sujeitos que, em regra, tem a autonomia no tocante à vivência e o desejo sexuais. O pesquisador deve nesse caminho tentar se despir dos preconceitos e tentar exercer a empatia. Como já foi dito, não há (ou, pelo menos, não deveria haver) uma hierarquia entre pesquisadores e pesquisados.

Uma maior inserção no campo dos Direitos Humanos permite ampliar o olhar para além da nossa própria realidade. Não é preciso ser uma pessoa com deficiência para defender o direito desse grupo social. A deficiência, ao contrário do que se costuma imaginar, não está no indivíduo, mas na própria sociedade, incapaz de lidar com a diferença e diversidade de vivências e formas de "ser" humano. Portanto, reconhecer as deficiências e limitações que estão em cada um de nós já constitui um importante passo para um futuro mais democrático.

\section{Referências}

Brasil. (2002). Lei $n^{\circ} 10.406$, de 10 de janeiro de 2002. Institui o Código Civil.

Brasil. (2002). Lei 13.146, de 6 de julho de 2015. Institui a Lei Brasileira de Inclusão da Pessoa com Deficiência (Estatuto da Pessoa com Deficiência).

Candau. V. M. Direitos Humanos, educação e interculturalidade: as tensões entre igualdade e diferença. Revista Brasileira de Educação. 13(37). 45-55. www.scielo.br/j/rbedu/a/5szsvwMvGSVPkGnWc67BjtC/?lang=pt. 
Candau. V. M. (2007). Educação em Direitos Humanos: desafios atuais. In: Dias, A. A., et al (org.). Educação em Direitos Humanos: fundamentos teóricometodológicos. (2007). 399-412. www.cchla.ufpb.br/ncdh/wp-content/uploads/2014/07/merged.compressed.pdf.

Diario de Pernambuco. (2018). Blogueira que comparou bebê com síndrome de Down a filhote de cachorro se desculpa com pais da criança na justiça. Www.diariodepernambuco.com.br/noticia/vidaurbana/2018/04/blogueira-que-discriminou-crianca-com-sindrome-de-down-presta-depoimento.html.

Fernandes, L. B., Mosquera, Carlos, \& Schlesener., Anita. (2011). Breve Histórico da Deficiência e seus Paradigmas. Revista do Núcleo de Estudos e Pesquisas Interdisciplinares em Musicoterapia 2. (132-144). http://www.fap.pr.gov.br/arquivos/File/extensao/Arquivos2011/NEPIM/NEPIM_Volume_0 2Art08_NEPIM_Vol02_BreveHistoricoDeficiencia.pdf.

Ferraz, C. V. Dos Direitos da Pessoa com Deficiência nas Relações Familiares. (2012). In: Ferraz, C. V., Leite, George Salomão, Leite, G. S., Leite, G. S. Manual dos Direitos da Pessoas com Deficiência, 322-341.

Foucault, M. (2014). A história da Sexualidade: a vontade de saber.

GODOY, A. S. (1995) Pesquisa qualitativa: tipos fundamentais. Revista de Administração de Empresas, 35(3), $20-25$.

Instituto Brasileiro de Geografia e Estatística (2010). Censo Demográfico. IBGE.

Jconline. (2018). Blogueira se desculpa por comentários contra criança com Down. https://jc.ne10.uol.com.br/canal/cidades/geral/noticia/2018/04/24/blogueirase-desculpa-por-comentarios-contra-crianca-com-down-336776.php .

Lage, A. C., \& Vieira, R. L. (2014). Movimento LGBT: uma escola de emancipação. Momento - Diálogos Em Educação, 23(1), 121-146. https://periodicos.furg.br/index.php/momento/article/view/4691.

Maranhão. G. C. Da S. C., Costa Filho, V. T., Alcantara, K. M.., \& Oliveira, P. V. B. "Somos perseguidas (...) e não podemos ter nossos filhos na paz": análise de um caso de violência obstétrica institucional durante o periodo da pandemia. In: Santiago, M. B do N., Barros, A. M. de. (Org.). (2020). Direitos Humanos em tempos de pandemia de coronavirus (e-book). 1, 149-157.

Maranhão. G. C. da S. C., Lima, M. R de S. G. de A., \& Craveiro, T. de S. (2017). Masculinidade hegemônica e os reflexos da construção do "homem de verdade”: uma análise da animação "minha vida de João”. III Seminário Internacional do Observatório dos Movimentos Sociais na América Latina.

Maranhão. G. C. Da S. C. Ministério Público de Pernambuco e a defesa do direito humano à educação da pessoa com deficiência: um estudo sobre a atuação das promotorias de educação do Recife (Dissertação de Mestrado). Universidade Federal de Pernambuco, Recife, PE, Brasil.

Mattos, Patrícia. O conceito de interseccionalidade e suas vantagens para os estudos de gênero no Brasil. (2011). In: Congresso Brasileiro de Sociologia, XV. Anais... Curitiba, Paraná.

Olesen, V. L. Os feminismos e a pesquisa qualitativa neste novo milênio. (2006). In: Denzin, N. K., Lincoln, Y. S \& colaboradores. O planejamento da pesquisa qualitativa: teorias e abordagens. Tradução de Sandra Regina Netz. 219-258.

Prado, V. J. do., \& Santos, L. R. dos. (2021). A inclusão das pessoas com deficiência (PCD) - um diálogo inexistente com a teoria organizacional. Research, Society and Development, 10(11). e289101119494. https://doi.org/10.33448/rsd-v-10i11.19694.

Passos. A. A., \& Teixeira-Machado, L. (2021). O entrelaçamento do movimento corporal expressivo da pessoa com deficiência no ambiente escolar. Research, Society and Development. 10(8), e48710817588. https://doi.org/10.33448/rds-v10i8.17588.

Rubin, G. (2003). Pensando o sexo: notas para uma Teoria Radical das Políticas da Sexualidade. Tradução de Felipe Bruno Martins Fernandes. Revisão de Miriam Pillar Grossi. Cadernos PAGU, 21.

Schwandt. T. A. Três posturas epistemológicas para a investigação qualitativa. (2006). In: Denzin, N. K., Lincoln,Y. S(org.). O planejamento da pesquisa qualitativa: teorias e abordagens. Tradução de Sandra Regina Netz., 193-217.

Santos. B. de S. (2019). Direitos Humanos: o desafio da interculturalidade. Revista de Direitos Humanos, 2.

Serra, I. O., Joca, T. T., A. R. M. N. de., \& Munguba, M. C. (2020). A pessoa com deficiência e os entrelaces com as questões de gênero e sexualidade. Research, Society and Development, 9 (8), e728986157. https://doi.org/10.33448/rds-v9i8.6157.

Unbehaum, S., et al. (2014). Programas e áreas de concentração em direitos humanos no Brasil: o desenho de uma possível interdisciplinaridade. Revista Interdisciplinar de Direitos Humanos, Bauru 2(3), 35-53. https://www3.faac.unesp.br/ridh/index.php/ridh/article/view/210/111.

Weeks, J. (2010). O corpo e a sexualidade. In. Louro, G. (org). O corpo educado: pedagogias da sexualidade, 2, $24-60$. 